\title{
DAS RECHT DER FREIHEIT, DE AXEL HONNETH.
}

\author{
Evânia Reich ${ }^{1}$ \\ Universidade Federal de Santa Catarina (UFSC)
}

\section{HONNETH, AXEL. DAS RECHT DER FREIHEIT. BERLIM: SUHRKAMP, 2011.}

Em Das Recht der Freiheit ${ }^{2}$, Honneth trabalha mais uma vez os três momentos da esfera do direito objetivo hegeliano com o intuito de mostrar que a liberdade dos indivíduos só é possível nas instituições cujas práticas normativas garantem um reconhecimento recíproco. Essas instituições são a realidade do mundo moderno onde a estrutura da liberdade subjetiva se encontra refletida de maneira objetiva.

PALAVRAS CHAVE: Liberdade social; Reconhecimento.

O novo livro de Honneth, que persegue sua investigação a cerca do papel do reconhecimento para a emancipação de uma sociedade a qual ele havia iniciado em Luta por reconhecimento (1992), não pode deixar de ser considerado, nas passagens em que a reatualização de Hegel se faz presente, como uma evolução da sua interpretação a respeito da teoria hegeliana do reconhecimento. Na presente resenha apresentarei as ideias principais a cerca da última obra de Honneth, $O$ direito da liberdade (2011), na parte em que o autor trabalha mais uma vez o conceito de reconhecimento em Hegel.

Para Honneth, Hegel nos seus escritos da juventude, influenciado pela filosofia aristotélica, dá um novo fundamento à ciência filosófica da sociedade substituindo as categorias atomísticas por uma base natural da socialização humana caracterizada pela existência de formas elementares de convívio intersubjetivo. Contudo, para o autor, Hegel, a partir da Realphilosophie (1805-1806), parte para uma teoria da consciência que infelizmente deixa de analisar essas formas essenciais de interação social e relações éticas para desenvolver as etapas da construção da consciência individual. Consequentemente, o modelo conceitual de uma luta por reconhecimento hegeliano perdeu, segundo Honneth, todo o seu significado teórico marcante. Isto é, "a construção do mundo social como um processo de aprendizagem

\footnotetext{
${ }^{1}$ Doutoranda em filosofia pela UFSC e bolsista CAPES.

${ }^{2}$ No interior do texto traduzimos o título da obra de Honneth por "O direito da liberdade".
} 
ético que conduz, passando por diversas etapas de uma luta, a relações cada vez mais exigentes de reconhecimento recíproco" (HONNETH, 2003, p. 112).

Em Sofrimento de indeterminação (2001) Honneth através de uma "reatualização" da Filosofia do direito entrever em duas esferas do direito objetivo, isto é, na família e na sociedade, momentos distintos de reconhecimento tal como Hegel já havia apontado nas obras da juventude ${ }^{3}$, com a esfera do amor, do trabalho e do direito. Contudo, o autor faz uma crítica no que tange a presença de um institucionalismo forte na Filosofia do direito (1821) que ofuscaria a compreensão de um reconhecimento recíproco horizontal. $O$ forte apego de Hegel a um institucionalismo que torna as estruturas administrada pelo Estado o único lugar eminente da ascensão da liberdade compreendida como "ser-consigo-mesmo-nooutro" permite apenas vislumbrarmos o reconhecimento de forma vertical. O estadismo hegeliano impõe uma estrutura "vertical" de subjugação que perverte inevitavelmente as relações "horizontais" de reconhecimento entre os indivíduos.

Em $O$ direito da liberdade, Honneth, contudo, não somente afirma que é possível ver a forma de reconhecimento recíproco horizontal no esquema lógico hegeliano da Filosofia do direito como também o adota para desenvolver a sua própria tese de que é somente através das instituições livres que os indivíduos conseguem alcançar a verdadeira liberdade que é aquela do tipo social. Se em Sofrimento de indeterminação Honneth ainda lamentava o abandono daquela primeira intuição hegeliana de um intersubjetivismo forte de base aristotélica, nesta última obra ele parece estar convencido de que não há nenhuma perda no conteúdo da doutrina filosófica de Hegel mesmo se as relações recíprocas de reconhecimento somente podem ser garantidas no contexto da sua doutrina da liberdade através de instituições ancoradas no decorrer de um processo histórico. Honneth não está mais preocupado em afirmar que o papel do reconhecimento na filosofia madura de Hegel, com a sua guinada para uma filosofia da consciência, se modifica deixando de lado o seu caráter formador da identidade dos indivíduos. Nesta obra, o foco principal da discussão é a liberdade dos indivíduos. É este conceito de "liberdade social" com o qual Honneth quer trabalhar que torna mais uma vez a leitura de Hegel tão instigante e promissora.

\section{Uma nova guinada honnethiana com o "Direito da liberdade"}

Neste novo livro Honneth revisita o papel central da categoria do reconhecimento para o conceito de liberdade social. Levando em consideração a filosofia hegeliana como um todo, Honneth interpreta o reconhecimento recíproco em Hegel como o "momento chave para a sua representação da liberdade" (HONNETH, 2011, p. 84). Para Hegel, segundo Honneth, os indivíduos não podem realizar suas finalidades através de suas experiências subjetivas. A realização da

\footnotetext{
${ }^{3}$ Em Luta por reconhecimento (1992) Honneth dedica os primeiros capítulos à compreensão do fragmento Sistema da eticidade (1802-1803) e a Realphilosophie (1805-1806) de Hegel.
} 
"verdadeira" liberdade de um indivíduo é somente possível na relação com o outro "cujas finalidades têm uma relação de complementaridade com as finalidades dele" (HONNETH, 2011, p. 84). As finalidades de seus parceiros sociais não são vistas pelos indivíduos como um entrave para a realização de seus próprios fins e aspirações. Ao contrário, seus desejos somente podem ser confirmados na medida em que a existência dos desejos e finalidades do outro é uma condição para a realização de seus próprios desejos e finalidades.

É a partir desta compreensão que o papel das instituições se torna indispensável. É somente através de instituições sociais reconhecidas historicamente que os indivíduos podem conhecer as finalidades e carências recíprocas. As instituições são o "médium" através do qual os indivíduos compreendem-se reciprocamente. Segundo Honneth, os sujeitos aprendem a articular para os outros de maneira compreensível suas finalidades assim como interpretam de maneira adequada os anseios desses, antes mesmo de poder se reconhecer reciprocamente como sendo dependentes uns dos outros. Isto é, faz-se necessário que os indivíduos se relacionem entre si no interior de instituições historicamente reconhecidas para que eles mesmos se reconheçam e se deem conta de suas dependências recíprocas. Sem este "médium" a tomada de consciência desta interdependência seria impossível. Essas instituições, contudo, não são quaisquer instituições forjadas pelos indivíduos, mas antes aquelas "destiladas da realidade histórica".

São as finalidades individuais que se complementam entre si que possibilitam a realização do reconhecimento recíproco. Os indivíduos se dão contam que vivem em uma sociedade no interior da qual seus anseios e objetivos têm que complementar àqueles de seus parceiros de interação. Eu reconheço o outro porque suas finalidades ecoam na minha própria vida e sou reconhecido porque minhas escolhas complementam as escolhas de meu parceiro social. As práticas institucionais funcionam como espelhos que refletem essas diferentes finalidades. Isto é, os sujeitos aprendem através das próprias práticas institucionalizadas a orientar seus motivos pelos fins internos destas, assim aquilo que em princípio poderia ser apenas uma vontade subjetiva se concretiza na realidade das instituições. Essas instituições através de suas práticas dão o sentido à verdadeira liberdade individual. Nessas práticas os indivíduos se conscientizam de suas dependências recíprocas para a realização de suas próprias liberdades. Portanto, diz Honneth, as instituições do reconhecimento são o fundamento e o local da realização da liberdade intersubjetiva ao mesmo tempo em que são o meio através do qual os indivíduos se compreendem como sujeitos livres.

A questão que Honneth ainda se coloca é a de saber como Hegel pode estabelecer de forma exaustiva aquelas finalidades que são compreendidas reciprocamente pelos indivíduos? Os três momentos da eticidade, isto é a família, a sociedade civil e o Estado, desenvolvidos na Filosofia do direito, podem ser

\footnotetext{
${ }^{4}$ Para Hegel as instituições de reconhecimento na modernidade são a família, a sociedade civil e o Estado.
} 
considerados suficientes para exprimir os locais onde os indivíduos forjam suas finalidades? Segundo Honneth, pode-se dizer que o método de reconstrução normativa empregado por Hegel é aquele que tenta equilibrar a realidade histórica com o ideal conceitual. Por um lado ele esboça de maneira conceitual os fins que todos os seres humanos deveriam se colocar racionalmente e por outro lado ele compara esses fins com as intenções empíricas as quais os indivíduos chegaram por terem crescido no interior de uma cultura moderna. As instituições da modernidade devem garantir que os sujeitos experimentem suas liberdades como algo objetivo. Isto é, aqueles fins que os indivíduos se dão racionalmente são colocados em práticas apenas no âmbito de instituições justas, o que apenas é possível no momento histórico da modernidade. Honneth não fala expressamente em seu texto se esses três momentos que compõe a esfera da eticidade são suficientes para abarcar as finalidades do homem moderno, contudo, também não faz aquela crítica que havia feito em Sofrimento de indeterminação quando se perguntava por que Hegel não introduziu os laços de amizade juntamente com a esfera da família (HONNETH, 2011, p. 130). Parece-nos, portanto, que nesta nova perspectiva de sua análise Honneth entende que essas três esferas históricas da eticidade conseguem envelopar todas as finalidades que os indivíduos modernos se põem. Além disso, não nos parece que nesta nova leitura, Honneth ainda considere que as três esferas da eticidade são ancoradas pelo direito positivo a fim de oferecer a condição para uma liberdade estável a todos os sujeitos (HONNETH, 2011, pp. 132-33). As práticas sociais inseridas dentro de instituições éticas compreendidas nesta leitura de $O$ direito da Liberdade parecem ultrapassar a esfera do direito positivo e constituir aquela característica da eticidade tão cara à Hegel, de segunda natureza.

Percebemos nesta retrospectiva da leitura de Honneth em $O$ direito da liberdade que há uma semelhança em muitos aspectos em relação aquilo que o autor já havia tratado em Sofrimento de Indeterminação. Contudo, não resta dúvida que Honneth aproveita as esferas do direito objetivo de uma maneira bem mais promissora para o desenvolvimento de sua teoria. A "reatualização" de Hegel é importante para fundamentar aquilo que Honneth designará de liberdade social. O conceito de reconhecimento, que parecia ofuscado em Sofrimento de Indeterminação pela crítica ao institucionalismo forte hegeliano, é explorado em todo o seu potencial nesta última obra. $\mathrm{O}$ autor frankfurtiano considera nessa sua última leitura que a Filosofia do direito não somente abarca aquele tipo de reconhecimento vertical, a saber, entre os indivíduos e as instituições, mas também parece aceitar um reconhecimento horizontal, isto é, entre os próprios indivíduos, na medida em que traz à tona essa afirmação de que as finalidades de cada indivíduo se complementam nas respectivas finalidades do outro. As instituições de reconhecimento são apenas o médium no interior da qual é possível esta relação recíproca de reconhecimento horizontal. 


\section{Referências bibliográficas:}

HEGEL, Georg Wilhelm Friedrich. Filosofia do direito. Trad. Paulo MENESES, Agemir BAVARESCO, Alfredo MORAES e outros. São Leopoldo, RS: UNISINOS, 2010 .

. O Sistema da Vida Ética. Trad. Artur MORÃO. Lisboa: Edições 70, 1991.

PUF, 2002. La Philosophie de l'esprit 1805. Trad. Guy PLANTY-BONJOUR. Paris:

HONNETH, Axel. Luta por Reconhecimento. Trad. Luiz REPA. São Paulo: Editora 34, 2003.

. Das Recht der Freiheit. Berlim: Suhrkamp, 2011.

Sofrimento de Indeterminação. Uma Reatualização da Filosofia do Direito de Hegel. Trad. Rúrion Soares Melo. São Paulo: Esfera pública, 2007. 